\title{
MORPHOLOGICAL AND HISTOLOGICAL EFFECTS OF BRUCEINE A ON THE LARVAE OF AEDES AEGYPTI LINNAEUS (DIPTERA: CULICIDAE)
}

\author{
DWI SUTININGSIH ${ }^{1 *}$, MUSTOFA MUSTOFA², TRI BASKORO TUNGGUL SATOTO³ ${ }^{3}$ EDHI MARTONO ${ }^{4}$
}

${ }^{1}$ Department of Epidemiology and Tropical Disease, Faculty of Public Health, University of Diponegoro, Semarang, Indonesia. ${ }^{2}$ Department of Pharmacology, Faculty of Medicine, Gadjah Mada University, Yogyakarta, Indonesia. ${ }^{3}$ Department of Parasitology, Faculty of Medicine, Gadjah Mada University, Yogyakarta, Indonesia. ${ }^{4}$ Department of Plant Pest and Diseases, Faculty of Agriculture, Gadjah Mada University, Yogyakarta, Indonesia. Email: Dwisuti98@gmail.com

Received: 15 May 2018, Revised and Accepted: 28 June 2018

\section{ABSTRACT}

Objective: This study aimed to determine a target of action of bruceine A on the basis of its morphological and histological effects on the larvae of Aedes aegypti Linnaeus.

Methods: Bruceine A was isolated from Brucea javanica (L.) Merr. seeds in accordance with the Mangungsong method. Larvae of A. Aegypti (L.) in instar III to the beginning of instar IV were treated with various concentrations of bruceine A. The negative control group did not receive any treatment, whereas the positive control group received 1 ppm temefos. Dead larvae were collected after $24 \mathrm{~h}$ of treatment for the examination of morphological and histological changes.

Results: The negative control group did not exhibit any morphological and histological changes. Larvae treated with bruceine A, however, had visible damaged heads, cuticles, digestive and respiration tracts, respiratory siphons, and setae, and they were smaller than normal larvae. Larvae treated with temefos exhibited gastrointestinal damage, narrowed breathing tubes, cuticle damage, and detached/damaged seta feathers. The necrosis of gastrointestinal epithelial cells was the major histological change exhibited by larvae treated with various concentrations of bruceine A or 1 ppm temefos.

Conclusion: The targets of action of bruceine A in A. aegypti (L.) larvae are the head/caput, cuticle, setae, siphon, and gastrointestinal and respiratory tracts.

Keywords: Bruceine A, Brucea javanica (L.) Merr., Action target, Morphology, Histology, Aedes aegypti Linnaeus.

(c) 2018 The Authors. Published by Innovare Academic Sciences Pvt Ltd. This is an open access article under the CC BY license (http://creativecommons. org/licenses/by/4. 0/) DOI: http://dx.doi.org/10.22159/ajpcr.2018.v11i10.27315

\section{INTRODUCTION}

Vector control is a method to suppress the incidence of vector-borne diseases. It is widely conducted as a public health intervention. Aedes aegypti Linnaeus is a mosquito species that is proved to be an important disease vector in tropical and subtropical regions [1]. A. aegypti (L.) is a vector of dengue fever, dengue hemorrhagic fever [2], chikungunya fever, yellow fever, and Zika viral disease [3]. The wide use of synthetic organic insecticides for vector control harms the environment and causes the emergence of insecticideresistant vectors, as well as the deaths of non-target animals. Earlier intervention studies have shown that although the use of synthetic insecticides such as temefos, especially in risky or potential places, can decrease disease transmission by mosquitoes, prolonged exposure to these chemicals will promote the adaptation, evolution, and selection of mosquitoes [4]. Thus, plant-derived insecticides/larvicides should be developed as another option for controlling vector-borne diseases. The two essential oils of Thymus vulgaris and Origanum majorana (Lamiaceae) demonstrate an interesting larvicidal activity. The 0 . majorana essential oil is more effective compared to the essential oil of $T$. vulgaris with an lethal concentration $50\left(\mathrm{LC}_{50}\right)$ of $107.13 \mu \mathrm{g} / \mathrm{mL}$ and $\mathrm{LC}_{90}$ of 365.90 $\mu \mathrm{g} / \mathrm{mL}$ on the malaria vector Anopheles labranchiae [5]. The crude ethanolic extract of Smilax larvata (Sarsaparilla) is a potential source of an eco-friendly larvicide against $A$. aegypti larvae with $\mathrm{LC}_{50} 225 \mu \mathrm{g} / \mathrm{mL}^{-1}$ and $\mathrm{LC}_{90} 350 \mu \mathrm{g} / \mathrm{mL}^{-1}$ [6]. Compounds from Brucea javanica (L.) Merr., have potential applications as agricultural insecticides. Zhang et al. [7] proved that brusatol isolated from $B$. javanica (L.) Merr. has insecticidal and antifeeding effects against the third-instar larvae of Spodoptera exigua. Brusatol can also induce apoptosis in the insect cell lines IOZCAS-Spec-II and Sf21. In these cell lines, apoptosis is characterized by DNA fragmentation, caspase- 3 activation, and cytochrome-c release from mitochondria. Sutiningsih and Nurjazuli [8] proved that brusatol isolated from the seeds of $B$. javanica (L) Merr has larvicidal activity against $A$. aegypti at the $\mathrm{LC}_{50}$ and $\mathrm{LC}_{90}$ of 0.669 and $8.331 \mathrm{ppm}$, respectively.

Bruceine A ([15]-3-methyl-2-butanoil-bruseolid) is a quassinoid derived from B. javanica (L.) Merr [9]. It has a molecular formula of $\mathrm{C}_{26} \mathrm{H}_{34} \mathrm{O}_{11}$ and has a mass of $522.54 \mathrm{~g} / \mathrm{mol}$. Physically, it is an amorphous powder with a bitter taste. Bruceine A has extensive broad biological activity as an antibabesiosis, antitrypanosomal, and anti-malarial as well as cytotoxic properties against cancer cell lines [10-12]. It also has insecticidal, antifeeding, and growthinhibiting activities against tobacco budworm (Heliothis virescens F.), Spodoptera frugiperda armyworm [13], and Mexican bean beetle larvae in the fourth instar (Epilachna varivestis Mulsant) [14]. Bruceine A can also act as a neurotoxin [15] and an inhibitor of growth [16] against the larvae of A. aegypti (L.) The biolarvicidal mechanism of the action of bruceine A occurs through the inhibition of acetylcholinesterase and VGSC gene. The behavioral responses of larvae treated with bruceine A include hyperexcitation, convulsions, paralysis, and aggressive biting of the anal gills; these behaviors indicate that bruceine A affects the larval neuromuscular systems [15]. Therefore, this study aimed to determine the targets of action of bruceine $A$ and to identify its effects on the morphology and histology of $A$. aegypti (L.) larvae. 


\section{METHODS}

\section{Materials}

Makassar fruit (B. javanica L. Merr) was purchased from a wholesaler of medicinal plants (Aneka Herbal Yogyakarta, Indonesia). Confirming its identity as well as obtaining its relevant scientific information, the specimen was further identified at the Laboratory of Pharmaceutical Biology, Faculty of Pharmacy, Gadjah Mada University, Yogyakarta, Indonesia. A. aegypti (L.) larvae in instar III to the beginning of instar IV were obtained from colonies maintained at the Laboratory of Parasitology, Faculty of Medicine, University of Gadjah Mada, Yogyakarta. All commercial reagents and other chemicals used in this study purchased from commercial suppliers were of analytical quality with the highest purity available. The selection of temefos dosage (1 ppm) was based on lethal damage consideration used in the field.

\section{Extraction and isolation of bruceine $A$}

Bruceine A was isolated from B. javanica (L.) Merr seeds in accordance with the method described by Mangungsong [17]. Dried seeds of B. javanica (L.) Merr (5 kg) were ground into powder and shaken with a hexane solution $(15 \mathrm{~L})$. The solution was then filtered and extracted with methanol $(15 \mathrm{~L})$. Methanol was evaporated to obtain a thick extract, which was then mixed with an equal volume of distilled water to form a suspension. Then, the suspension was partitioned with hexane $(3 \mathrm{~L})$. After, the hexane fraction was separated from the suspension, and methanol-water fractions were collected for repeated extraction with dichloromethane $(1 \mathrm{~L})$. Later, the organic layer was collected and evaporated to obtain a concentrate, which was then diluted with methanol $(100-250 \mathrm{~mL})$ at $60^{\circ} \mathrm{C}$ and stored at room temperature. The methanol solution was maintained at room temperature to allow the crystallization of bruceine A. Further separation was conducted through filtration. The remainder of the filtrate/residue was separated through thin-layer chromatography (TLC) and evaporated. Finally, purity levels of the amorphous powder were measured using high-performance liquid chromatography (HPLC).

\section{Morphological test}

Morphological tests were conducted in accordance with the method reported by Sharma et al. [18] with slight modifications. A. aegypti (L.) larvae in instar III to the beginning of instar IV were placed in glass jars, each containing $199 \mathrm{~mL}$ of water and $1 \mathrm{~mL}$ of bruceine A at various LC or $1 \mathrm{ppm}$ of the positive control temefos. Negative controls were treated with distilled water. The larvae found dead after $24 \mathrm{~h}$ were separated and studied under light microscopy to examine its morphology. Larvae were scrutinized after mounting with Hoyer's medium and morphological changes in body segments including the head, setae, cuticle, abdomen, and anal gills. They were observed, photographed, and compared with those of the controls.

\section{Histological test}

Histological tests were performed in accordance with the method of Narciso et al. [19] with slight modifications. Larvae treated with different concentrations of bruceine A, $1 \mathrm{ppm}$ of temefos, or distilled water were fixed in $2.5 \%$ glutaraldehyde in sodium cacodylate buffer $(0.1 \mathrm{M}, \mathrm{pH}$ 7.4) for $4 \mathrm{~h}$. Samples were then dehydrated in a gradient ethanol series $(70 \%, 80 \%, 90 \% 96 \%$, and 100\%). Samples were immersed in each ethanol solution for $15 \mathrm{~min}$. Samples were embedded in Historesin JB4, and the resulting blocks were sliced using a microtome to obtain a series of $3 \mu \mathrm{m}$ thick sections. These sections were stained with hematoxylin-eosin and then examined and photographed using a light microscope. Morphological and histological changes in larvae were analyzed descriptively.

\section{RESULTS AND DISCUSSION}

Isolation of bruceine A from B. javanica L. Merr

Based on the extraction and isolation method by Mangungsong [17], as much as $150 \mathrm{mg}$ of isolate compounds of bruceine A was obtained from each of $5 \mathrm{~kg}$ of Makassar fruit (B. javanica L. Merr). The purity levels of the amorphous powder were measured using two-dimensional chromatography with stationary phase silica gel 60 F254 on TLC plate and mobile phase of mixed solvent of chloroform and ethyl acetate with ratio of 1:2 to produce a single purple spot seen in ultraviolet (UV) $366 \mathrm{~nm}$ with retardation factor (Rf) of 0.88 . The results of this research are in line with the results from Mangungsong [17] which suggested that there was a single purple spot on bruceine A isolate under UV ray $366 \mathrm{~nm}$ observation. The purple spot indicated that bruceine A isolate is single/pure apart from other chemical components [20]. Rf value of bruceine A isolate of 0.8 is still considered as an ideal average value that is between 0.2 and 0.8 . Rf value is the distance traveled by compound divided by distance traveled by eluent. Higher Rf value showed that isolate/ chemical compound has low polarity and otherwise [21]. The result of a calculation based on area under the graph of the HPLC of bruceine A isolate showed a single dominant peak with area width percentage of $92.796 \%$ and retention time (Rt) of $4.633 \mathrm{~min}$. Although bruceine A compound has not reached $99-100 \%$, bruceine A isolate compound inside the isolate is shown with a single dominant peak on the produced chromatograph. The result of this research is not very different from Mangungsong [17] which showed that the pureness of bruceine A isolate was of $94.88 \%$ with a Rt of $4.83 \mathrm{~min}$.

\section{Morphological changes of $A$. aegypti (L.) larvae}

Observation on morphological changes in A. aegypti (L.) larvae was meant to decide damaged target body part after the treatment with bruceine $\mathrm{A}$ at various concentrations comparing the treatment with a control larvae. An overview of the morphological changes is presented in Figs. 1 and 2.

Bodies of control larvae did not show any damages (Fig. 1a). Those larvae treated with $1 \mathrm{ppm}$ temefos exhibited damaged cuticles and digestive tracts with some dark spots narrowed breathing tubes and some detached/damaged setae feathers (Fig. 1b). By contrast, larvae treated with lowest concentrations of bruceine A (1 ppm) exhibited morphological damage to the head, which appeared dark, and some parts of the cuticle layer, as well as narrowed breathing tubes (Fig. 2a). At the higher concentration, bruceine A ( 2 ppm) damaged or caused the detachment of anal papillae/anal gills, as well as decreased body size and caused discoloration (Fig. 2b).

These results are consistent with previous studies confirming that larvae of A. aegypti (L.) treated with bruceine A at sub-LC (0.2 ppm) cause damage to their digestive with the existence of black spots, folded respiratory tubes, and detached setae and cuticles [16]. The research of Warikoo and Kumar [22] reported that treatment with excess Argemone mexicana damaged the anal papillae of A. aegypti larvae. Sharma et al. [18] showed that treatment with extracts of the stems and leaves of Achyranthes aspera caused a structural damage to the anal papillae of larvae of $A$. aegypti in the early fourth instar. In the present study, microscopic observations showed that the

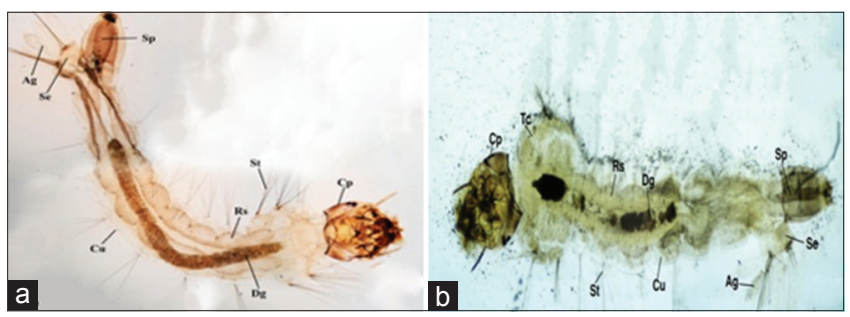

Fig. 1: Microscopic images of control and temefos-treated Aedes aegypti (L.) larvae. (a) control larva (untreated), $\times 40$. The heads, thoraxes, and abdomens of larvae are still complete, (b) temefostreated $(1 \mathrm{ppm})$ larva, $\times 100$. Respiratory and digestive tract are severely damaged, cuticle, and setae are damaged/detached. Cp: Caput, Dg: Digestive tract, Rs: Respiratory tract, St: Setae, Cu: Cuticle, Sp: Siphon, Se: Saddle, Ag: Anal gills 


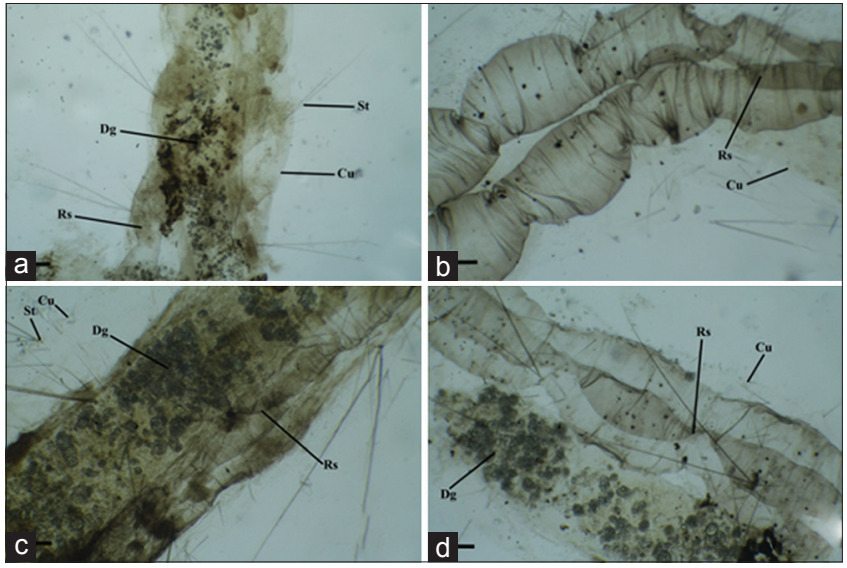

Fig. 2: Microscopic images of Aedes aegypti (L.) larvae treated with (a) 1 ppm, (b) 2 ppm, (c) 4 ppm, and (d) 8 ppm bruceine A, $\times 100$. Larvae of $A$. aegypti (L.) treated with various concentrations of bruceine A exhibited damaged digestive and respiratory tract, numerous loose setae and cuticle, and damaged siphons. Rs: Respiratory tract, Cu: Cuticle, Dg: Digestive tract, St: Setae

internal membranes of anal papillae were shrank, whereas external membranes were remained normal. As reported by Insun et al. [23], the larvae of Culex quinquefasciatus treated with ethanol extracts of Kaempferia galanga exhibited anal papillae damage and cuticle shrinkage. According to Chaithong et al. [24], the structural deformity of the anal papillae may result from osmotic and ionic dysregulation. Thus, osmotic and ionic dysregulation is possible causes of death of the larvae of A. aegypti (L.).

Observation of morphology of A. aegypti (L.) larvae after the treatment with $4 \mathrm{ppm}$ of bruceine A showed swollen digestive tracts, narrowed and folded respiratory tubes, damaged cuticle, and detached setae feathers (Fig. 2c). Larvae treated with the highest concentration of bruceine A (8 ppm) exhibited darkened heads with black spots, swollen or lysed digestive tracts with some blackened areas, small and highly folded respiratory tubes, enlarged siphons, and damaged cuticle and setae feathers (Fig. 2d). The higher the concentration of bruceine $\mathrm{A}$, the worse and more widespread of A. aegypti (L.) larvae morphological damages is to cause damage to the digestive tract and cuticle. In addition, respiratory tubes, siphon, and anal gills were having more severe damage. These results are similar to those observed by Sharma et al. [18], who reported that the larvae of A. aegypti exhibited distorted midguts, pigmentation loss, and partial or total cell damage after treatment with extracts from the stems and leaves of $A$. aspera. Digestive tract damage was more visible in larvae treated with the hexane extract of $A$. aspera leaves than those treated with extracts from $A$. aspera stems. Light/electron microscopic observations at $6,12,24$, and $48 \mathrm{~h}$ after $A$. aspera treatment showed that midgut epithelial damage intensified over time. Chaithong et al. [24] reported that pepper extract had similar effects on the midguts of $A$. aegypti larvae.

Based on the results of this study, it proves that toxic substances in bruceine A cause morphological damage in the body of A. aegypti (L.) larvae. Bruceine A acts as a contact poison to the gastrointestinal and respiratory systems and likely enters the larval body through the pores of the skin/cuticle, digestive tract, and siphon. Bruceine A is a nonpolar compound that is soluble in the lipids of the insect cuticle. Being soluble in lipids accelerates its rate of penetration into the insect hemocoel (body cavity). The penetration rate of bruceine A through the cuticle depends on cuticle structure and thickness [25]. Toxic substances generally tend to penetrate through larval body parts that are thinly coated with cuticle; examples of such body parts include intersegmental membranes, membrane joints, and chemoreceptors on the tarsus [26]. Bruceine $\mathrm{A}$ is absorbed by the body wall of insects and taken by body fluids to the active target area. It causes the dysfunction of the digestive, respiratory, and nervous systems of larvae [27]. Toxic substances enter the skin membrane of larva through simple diffusion [28]. These compounds then damage skin cells, causing the skin membrane to lose its impermeability and thus allowing other free toxic compounds to penetrate into the larval body. Toxic compounds also damage proteins in the skin membrane, thus disturbing the function of the skin as the protector of the body [29]. In addition to diffusion through the skin, toxic substances enter through the digestive tract [30]. The digestive tract of the mosquito larva consists of the anterior, mid, and posterior parts [31]. Food digestion and nutrient absorption occur in the midgut [29]. The insect midgut is covered with epithelial tissue. Toxic substances enter through the mouth of the larva and continue to the midgut while lysing epithelial cells. Cell lysis decreases the surface tension of mucous membranes ultimately inhibiting digestion and nutrient absorption [26,31]. Toxic substances may also penetrate the larval body through respiratory tracts. Air enters through a siphon attached to the water surface. Thus, toxic substances covering the surface of the water medium prevent the siphon from obtaining oxygen. Wulandari et al. [32] stated that secondary metabolites can interfere with oxygen collection. Given that the neural networks of larvae are highly sensitive to oxygen balance, neural atrophy and siphon damage may hinder breathing and eventually cause larvae to die.

Meanwhile, A. aegypti (L.) larvae treated with temefos 1 ppm caused damage on the entire body (Fig.1b). The body size of the larvae shrinks compared to its body size after treatment with bruceine $A$ and control (untreated). The result of this research is not very different from Yulidar and Hadifah [33] which showed the morphological damages of $A$. aegypti larvae on the head, thorax, abdomen, and detached setae feathers, and shrinking body size after treatment with temefos at LC. This is thought to happen because of the differences in water content inside larvae's body and the environment, so the water from the body is released through abdominal sockets and moved out to the environment. According to Badyaev [34], water transmission from larvae's body is caused by high temefos contain in the medium. This in turn lead to higher pressure of osmotic environment. The higher temefos concentration on water media brings about water content in the body of larvae getting higher and the differences in osmotic pressure happen. The balance of osmosis chemical solution can transpire through diffusion [35]. On the dead larvae, there is water movement from higher water molecules in the environment to the inner part of A. aegypti (L.) larvae that have lower osmotic pressure [36]. Allegedly, this is what causes the outer layer of the abdomen is seen shrinking because the water from inside of larvae's body is leaked outside.

Temefos likely gets into the bodies of larvae through cuticle contact, inhalation, and/or ingestion [37]. Temefos contains phosphorothioate, a lipophilic group. Thus, it easily penetrates the hydrophilic epicuticular parts of A. aegypti (L.) larvae and causes the cuticle and setae feathers to detach from the bodies of larvae [38]. After penetrating the cuticle/skin, temefos then enters nerve cells in the gastrointestinal and respiratory tracts of larvae. Temefos poisoning is characterized by restlessness, hyperexcitability, tremors, convulsions, and eventually muscle paralysis [38]. In addition to the cuticle, temefos enters the larval body through the respiratory tract, thus causing the breathing tube to shrink. Temefos also enters the larval body when consumed with food in breeding media [37].

\section{Histological changes of A. aegypti (L.) larvae}

The histomorphological analysis was conducted to gain further insight into the targets of action of bruceine $\mathrm{A}$ in the larvae of $A$. aegypti (L.). Figs. 3 and 4 show the differences between the histology of control larvae and temefos with that of larvae treated with LC of bruceine $\mathrm{A}$. 
Gastrointestinal epithelial cells from the control A. aegypti (L.) larvae were normal with compactly stained cytoplasm, spherical nuclei, clearly defined chromatin, and visible peritrophic membranes. Moreover, the majority of microvilli appeared normal where epithelial cells remained attached to the basement membrane (Fig. 3a). Larvae treated with $1 \mathrm{ppm}$ temefos exhibited necrotic, shrunken, and diffuse gastrointestinal epithelial cells with karyopyknotic nuclei. Necrotic epithelial cells remained attached to the basement membrane. Necrotic microvilli and peritrophic membranes appeared diffuse, and epithelial cells appeared disorganized (Fig. 3b).

A. aegypti (L.) larvae treated with the low concentration of $1 \mathrm{ppm}$ bruceine A exhibited necrotic gastrointestinal epithelial cells that remained attached to the basement membrane. Microvilli and peritrophic membranes became diffuse and necrotic, and epithelial cells became structurally disorganized (Fig. 4a). The same comprehensive histological changes were also observed in A. aegypti (L.) larvae treated with bruceine $A$ at concentrations of 2 and $4 \mathrm{ppm}$ (Fig. $4 \mathrm{~b}$ and c). It showed that the higher the concentration of bruceine a, the worse the damage of the body of A. aegypti (L) larvae. Larvae treated with $8 \mathrm{ppm}$ bruceine A exhibited completely diffuse necrotic gastrointestinal epithelial cells which completely detached from the basement membrane and localized in the lumen. These results are consistent with that reported by Sharma et al. [18] who stated that midgut epithelial cells exhibited intense damage at $6,12,24$, and $48 \mathrm{~h}$ after treatment with $A$. aspera extract. Highly typical changes include the vacuolization of midgut columnar cells, damage to microvilli, the release of epithelial cell content into the midgut lumen, and eventual cell death. Sutiningsih et al. [16] report that there was necrosis on gastrointestinal epithelial cells indicated by shrunken cells and diminished core (karyolysis) on A. aegypti (L.) larvae after treatment with bruceine $\mathrm{A}$ at the sub-lethal dosage $(0.2 \mathrm{ppm})$. The results from Patil et al. [39] showing that there were extruded peritrophic membrane on posterior peak between anal papilla on the $\operatorname{dead} A$. aegypti (L.) larvae after treated with Clerodendron inerme extract at LC. The extruded peritrophic membrane indicated that $C$. inerme extract affected the intestinal area that can cause a substantial effect on nutrition absorbing and inhibition of larvae's development process. The peritrophic membrane is a sheath containing acellular chitin that separates the content of intestines from secretory epithelial/ intestinal absorption that also acts as a barrier for pathogens which protect the area of midgut [40-42].

Narciso etal. [19] reported that histomorphologicalchanges resulted from treatment with burchelin from Ocotea cymbarium caused the death of L3-L4 larvae of A. aegypti. The midgut epithelial cells of the larvae exhibited disorganization, damage, and vacuolization. The histological analysis of larvae of Culex nigripalpus infected by Bacillus thuringiensis Medelin (Cry 11Bb) [42] revealed similar damages as that observed in the intestinal cells of Aedes albopictus infected by B. thuringiensis var Israelensis (Bti) [43]. Infection is characterized by the presence of rounded mesenteric cells with granular cytoplasm, absent or clear nucleus, and cytoplasmic vacuolization. The mesentery actively participates in secretion and absorption. The disintegration of mesentery cells occurs through the accumulation of granular material in the apical part followed by the release of material into the gut lumen. Mosquito larvae treated with the tested substance exhibited gastric vacuolization, cellular disorganization within intersegmental cells, and clear or absent nucleus. These comprehensive changes are not limited to chemical damage; infection with Baculovirus resulted in the same changes to the gastric and Malpighian tubules of $C$. nigripalpus Theobald larvae [42].

Al-Mehmadi and Al-Khalaf [44] stated that histopathological changes are qualitatively different in terms of localization and quantitatively correspond to the duration or length of observation time. Histopathological effects on the midgut and gastric ceca

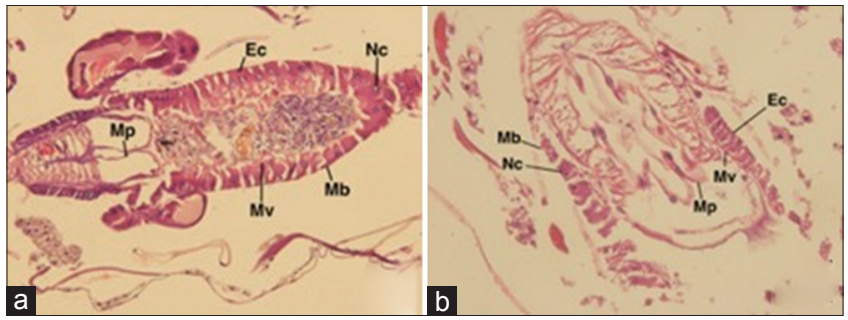

Fig. 3: Longitudinal sections of gastrointestinal tracts from Aedes aegypti (L.) larvae. (a) control larvae, $\times \mathbf{4 0 0}$. Gastrointestinal epithelial cells are normal with compactly stained cytoplasm,

(b) temefos-treated larva $(1 \mathrm{ppm}), \times 400$. Gastrointestinal epithelial cells are necrotic. Mb: Basement membrane, Ec: Epithelial cells, Mv: Microvilli, Mp: Peritrophic membrane, Nc: Nucleus

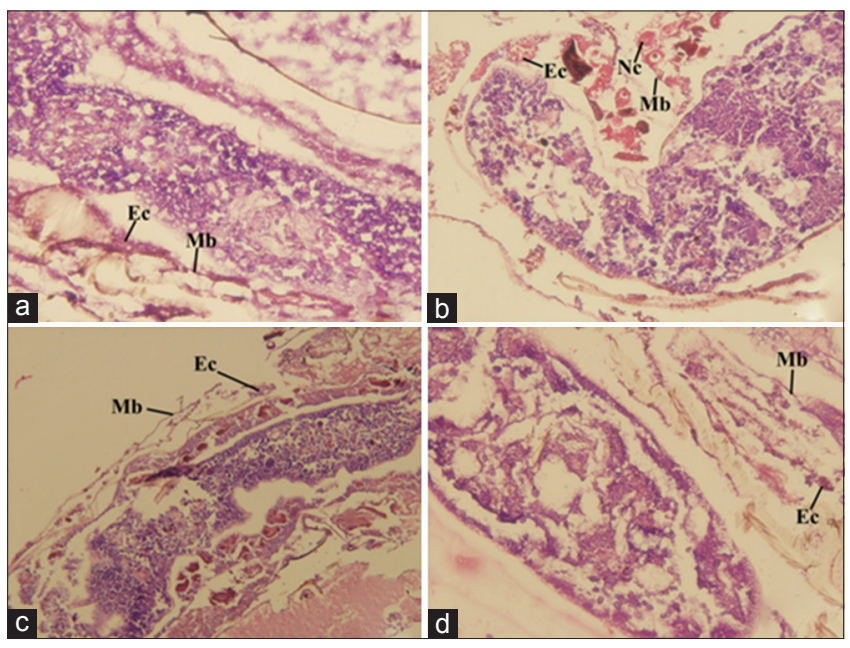

Fig. 4: Longitudinal sections of gastrointestinal tracts from Aedes aegypti (L.) larvae treated with (a) 1 ppm bruceine A,

(b) 2 ppm bruceine A, (c) 4 ppm bruceine $A$, (d) 8 ppm bruceine A, $\times 400$. A. aegypti (L.) larvae treated with various concentrations of bruceine A exhibited diffuse necrotic epithelial cells. Mb: Basement membrane, Ec: Epithelial cells, Mv: Microvilli, Mp: Peritrophic membrane

confirmed that these areas are in direct contact with toxic substances. C. quinquefasciatus larvae treated with Melia azedarach extract exhibited serious damage and necrotic columnar epithelial cells of the gastric ceca. At $24 \mathrm{~h}$ after treatment, the epithelial cells of the gastric ceca exploded or shrunk and underwent lysis. Changes were also observed in the anterior and posterior of the midgut which showed epithelial cells detached from the basal membrane with peritrophic membrane damage and cell wall rupture [44]. The mixing of intestinal contents with hemolymph causes larvae to die. Assar and ElSobky [45] also observed that aqueous hyacinth extracts can severely damage the larval midgut. They reported that damage after 48 and $72 \mathrm{~h}$ of observation is characterized by vacuolization and shrinkage of epithelial cells.

Bruceine $\mathrm{A}$ is a toxic substance which may enter the digestive tract through the skin or buccal membrane. This toxic substance first causes midgut epithelial cells to undergo lysis or necrosis. Cell death or lysis, in turn, decreases the surface tension of the mucous membranes of the midgut to inhibit the digestion and absorption of food, ultimately resulting in larval death [29]. The results of this study prove that bruceine A is a potential natural larvicide that can be used to control the population of A. aegypti (L.) larvae as disease vectors. Its targets of action for morphological damage include the head, cuticle, setae, siphons, and gastrointestinal and respiratory tracts, whereas those of histological damage is the midgut or gastrointestinal epithelial cells. 
It is necessary to conduct further research on larvicidal action target of bruceine A on different species of mosquitoes as well as a detailed microscopic examination on body parts of larvae using transmission electron microscope.

\section{CONCLUSION}

Larvicidal action targets of bruceine $\mathrm{A}$ are as follows: (a) Morphologically damage the head, cuticles, setae, digestive and respiratory tracts, and siphon and (b) histologically damage by causing necrosis on gastrointestinal epithelial cells, peritrophic membrane, microvilli, and disorganized epithelial cells, detached from basalis membrane.

\section{ACKNOWLEDGMENTS}

The authors are deeply grateful to Sitarina Widyarini, P.hD, Sugiyono, M.Sc and Rr. Upik Ngesti WA, M.Biomed from Gadjah Mada University who helped in the reading of morphological and histological preparations in this study.

\section{AUTHOR'S CONTRIBUTION}

Dwi Sutiningsih: Conceived and designed the experiments, reviewed literatures, and wrote the manuscript. Mustofa: Performed the experiments and contributed to analyzing result and writing manuscript. Tri Baskoro Tunggul Satoto: Performed morphological and histological analysis. Edhi Martono: Designed the research plan and contributed to writing manuscript.

\section{CONFLICTS OF INTEREST}

The authors have no conflict of interest or financial interest in regard to the result of the research.

\section{REFERENCES}

1. Morrison AC, Zielinski-Gutierrez E, Scott TW, Rosenberg R. Defining challenges and proposing solutions for control of the virus vector Aedes aegypti. PLoS Med 2008;5:e68.

2. Ponlawat A, Scott JG, Harrington LC. Insecticide susceptibility of Aedes aegypti and Aedes albopictus across thailand. J Med Entomol 2005;42:821-5.

3. Jansen CC, Beebe N. The dengue vector of Aedes aegypti: What comes next. Microbes Infect 2010;12:272-9.

4. Sanchez L, Vanlerberghe V, Alfonso L, Marquetti Mdel C, Guzman MG, Bisset $\mathrm{J}$, et al. Aedes aegypti larval indices and risk for dengue epidemics. Emerg Infect Dis 2006;12:800-6.

5. El-Akhal F, Guemmouh R, Maniar S, Taghzouti K, El Quali Lalami A. Larvicidal activity of essential oils of Thymus vulgaris and Origanum majorana (Lamiaceae) against of the Malaria vector Anopheles labranchiae (Diptera: Culicidae). Int J Pharm Pharm Sci 2016;8:372-6.

6. Hirota BC, De Oliveira CD, Merino FJ, Verdam MC, Da Silva CB, Murakami FS, et al. Larvicide and antifungal activities of Sarsaparilla (Smilax larvata) extracts. Int J Pharm Pharm Sci 2015;7:308-11.

7. Zhang L, Feng X, Ma D, Yang J, Jiang H, Zhang Y, et al. Brusatol isolated from Brucea javanica (L.) merr. Induces apoptotic death of insect cell lines. Pestic Biochem Physiol 2013;107:18-24.

8. Sutiningsih D, Nurjazuli N. Effect of brusatol biolarvicide administration on behavioral response of Aedes aegypti and its toxicity on vero cells. J Biol Sci 2017; 17:127-35

9. Bawm S, Matsuura H, Elkhateeb A, Nabeta K, Subeki, Nonaka N, et al. In vitro antitrypanosomal activities of quassinoid compounds from the fruits of a medicinal plant, Brucea javanica. Vet Parasitol 2008;158:288-94

10. Pan L, Chin YW, Chai HB, Ninh TN, Soejarto DD, Kinghorn AD, et al. Bioactivity-guided isolation of cytotoxic constituents of Brucea javanica collected in vietnam. Bioorg Med Chem 2009;17:2219-24.

11. Elkhateeb A, Yamasaki M, Maede Y, Katakura K, Nabeta K, Matsuura H. Anti-babesial quassinoids from the fruits of Brucea javanica. Nat Prod Commun 2008;3:145-8.

12. Subeki, Matsuura H, Takahashi K, Nabeta K, Yamasaki M, Maede Y, et al. Screening of indonesian medicinal plant extracts for antibabesial activity and isolation of new quassinoids from Brucea javanica. J Nat Prod 2007:70:1654-7.
13. Klocke J, Arisawa M, Handa S, Kinghorn A, Cordel I, Farnsworth N. Growth inhibitory, insecticidal and antifeedant effects of some antileukemic and cytotoxic quassinoids on two species of agricultural pest. Chem Org Naturst 1985;47:222-64.

14. Leskinen V, Polonsky J, Bhatnagar S. Antifeedant activity of quassinoids. J Chem Ecol 1984;10:1497-507.

15. Sutiningsih D, Mustofa M, Satoto TB, Martono E. Neurotoxic mechanism of bruceine A biolarvicide against Aedes aegypti linnaeus larvae. Res J Med Plants 2017;11:77-85.

16. Sutiningsih D, Mustofa M, Satoto TB, Martono E. Inhibitory effects of bruceine A biolarvicide on growth and development of Aedes aegypti larvae. J Entomol 2017;14:104-11.

17. Mangungsong S. The Activity of Semisynthetic Quassinoid Compound from Makassar Fruit (Brucea javanica L. Merr) as Anticancer with Target Protein p53, Bcl-2, Caspase- 3, COX-2, and c-Myc. Ph. D Thesis. Faculty of Medicine, Gadjah Mada University, Yogyakarta; 2012.

18. Sharma A, Kumar S, Tripathi P. Impact of Achyranthes aspera leaf and stem extracts on the survival, morphology, and behaviour of an Indian strain of dengue vector, Aedes aegypti. J Mosq Res 2015;5:1-9.

19. Narciso JO, Soares RO, Reis dos Santos Mallet J, Guimarães AÉ, de Oliveira Chaves MC, Barbosa-Filho JM, et al. Burchellin: Study of bioactivity against aedes aegypti. Parasit Vectors 2014;7:172.

20. Bogoriani N. Isolation and identification steroid glycosides from andong leaves (Cordyline terminalis Kunth). J Chemistry 2008;2:40-4.

21. Barbosa LF, Braz-Filho R, Vieira IJ. Chemical constituents of plants from the genus simaba (Simaroubaceae). Chem Biodivers 2011;8:2163-78.

22. Warikoo R, Kumar S. Impact of Argemone mexicana extracts on the cidal, morphological, and behavioral response of dengue vector, Aedes aegypti L. (Diptera: Culicidae). Parasitol Res 2013;112:3477-84.

23. Insun D, Choochote W, Jitpakdi A, Chaithong U, Tippawangkosol P, Pitasawat B, et al. Possible site of action of Kaempferia galanga in killing Culex quinquefasciatus larvae. Southeast Asian J Trop Med Public Health 1999;30:195-9.

24. Chaithong U, Choochote W, Kamsuk K, Jitpakdi A, Tippawangkosol P, Chaiyasit D, et al. Larvicidal effect of pepper plants on aedes aegypti (L.) (Diptera: Culicidae). J Vector Ecol 2006;31:138-44.

25. Chen YY, Pan QD, Li DP, Liu JL, Wen YX, Huang YL, et al. New pregnane glycosides from Brucea javanica and their antifeedant activity. Chem Biodivers 2011;8:460-6.

26. Dono D, Ismayana S, Idar, Prijono D, Muslikha I. Status and biochemical resistance of Crocidolomia pavonana (F.) (Lepidoptera: Crambidae) to organophosphate insecticide and its sensitivity to botanical insecticide. Indo J Entomol 2010;7:9-27.

27. Isman MB. Botanical insecticides, deterrents, and repellents in modern agriculture and an increasingly regulated world. Annu Rev Entomol 2006;51:45-66.

28. Kringer R. Handbook of Pesticide Toxicology. California: Academic Press; 2010.

29. Lu FC, Kacew S. Lu's Basic Toxicology: Fundamentals, Targets Organ and Risk Assessment. $4^{\text {th }}$ ed. New York: Taylor and Francis; 2002.

30. Herms WB. Medical Entomology. $6^{\text {th }}$ ed. New York: Macmillan; 1969.

31. Alves IA, Miranda HM, Soares LA, Randau KP. Simaroubaceae family: Botany, chemical composition, and biological activities. Rev Bras Farmacogn 2014;24:481-501

32. Wulandari S, Arnetis A, Rahayu S. Potential of sap papaya fruit (Carica papaya L) against mortality of Aedes albopictus mosquitoes larvae. Biogenesis 2012;9:69-75.

33. Yulidar Y, Hadifah Z. The abnormalities of larvae's morphology after temephos exposure in phase larvae instar 3 (L3). J Buski 2014;5:23-8

34. Badyaev AV. Stress-induced variation in evolution: From behavioural plasticity to genetic assimilation. Proc Biol Sci 2005;272:877-86.

35. Thavara U, Tawatsin A, Srithommarat R, Zaim M, Mulla MS. Sequential release and residual activity of temephos applied as sand granules to water-storage jars for the control of Aedes aegypti larvae (Diptera: Culicidae). J Vector Ecol 2005;30:62-72.

36. Chen CD, Lee HL. Laboratory bioefficacy of CREEK 1.0G (temephos) against aedes (Stegomyia) aegypti (Linnaeus) larvae. Trop Biomed 2006;23:220-3.

37. Matsumura F. Toxicology of Insecticides. $2^{\text {nd }}$ ed. New York: Plenum Press; 1985

38. Yu S. The Toxicology and Biochemistry of Insecticides. Boca Raton: CRC Press; 2008.

39. Patil PB, Kallapur SV, Kallapur VL, Holihosur SN. Larvicidal activity of Clerodendron inerme gaertn extracts against Aedes aegypti L. and 
Culex quinquefasciatus Say. Mosquito species. Asian J Pharm Clin Res 2014;7 Suppl 1:206-9.

40. Jordan TV, Shike H, Boulo V, Cedeno V, Fang Q, Davis BS, et al. Pantropic retroviral vectors mediate somatic cell transformation and expression of foreign genes in Dipteran insects. Insect Mol Biol 1998; 7:215-22.

41. Tellam RL, Wijffels G, Willadsen P. Peritrophic matrix proteins. Insect Biochem Mol Biol 1999;29:87-101.

42. Moser B, Becnel J, White S, Alfonso C, Kutish G, Shanker S, et al. Morphological and molecular evidence that Culex nigripalpus baculovirus is an unusual member of the family baculoviridae. J Gen Virol 2001;82:283-97.
43. Silva VC, Pinheiro NL, Scherer PO, Falcão SS, Ribeiro VR, Mendes RM, et al. Histology and ultrastructure of Aedes albopictus larval midgut infected with Bacillus thuringiensis var. Israelensis. Microsc Res Tech 2008;71:663-8.

44. Al-Mehmadi R, Al-Khalaf A. Larvicidal and histological effects of Melia azedarach extract on Culex quinquefasciatus say larvae (Diptera: Culicidae). J King Saud Univ 2010;22:77-85.

45. Assar AA, el-Sobky MM. Biological and histopathological studies of some plant extracts on larvae of Culex pipiens (Diptera: Culicidae). J Egypt Soc Parasitol 2003;33:189-200. 